\title{
Aplicações da criatividade na educação brasileira
}

\author{
Applications of creativity in Brazilian education
}

\author{
Jan Raphael Reuter Braun ${ }^{[a]}$, Francisco Antonio Pereira Fialho ${ }^{[b]}$, Luiz Salomão \\ Ribas Gomez ${ }^{[b]}$ \\ [a] Faculdade SATC, Criciúma, SC, Brasil \\ [b] Universidade Federal de Santa Catarina, Florianópolis, SC, Brasil
}

\section{Resumo}

$\mathrm{O}$ artigo discute relações entre o ensino brasileiro e a criatividade; e exemplifica este conteúdo com a apresentação de quatro práticas que estimulam a criatividade e contribuem para o aprendizado escolar. Para isso o estudo se classifica como qualitativo, utilizando de procedimentos técnicos: pesquisa bibliográfica e estudo de casos. Observou-se que parte do problema relacionado ao interesse e permanência do aluno no sistema de ensino brasileiro pode ser solucionado utilizando práticas criativas que estimulem o interesse e contribuam para a compreensão dos conteúdos apresentados.

Palavras chave: Ensino. Prática criativa. Formação do indivíduo.

* JRRB: Doutorando em Design, e-mail: jrrbraun@gmail.com

FAPF: Doutor em Engenharia de Produção e Conhecimento, e-mail: fapfialho@gmail.com

LSRG: Doutor em Engenharia da Produção, e-mail: salodesigner@gmail.com 


\section{Abstract}

This paper discusses relations between the Brazilian education and creativity; and exemplifies this content through four practices that stimulate creativity and contribute to learning. For this, the study is classified as qualitative using technical procedures: literature review and case studies. It was observed that part of the problem related to interest and retain the student in the Brazilian education system can be solved using creative practices that stimulate interest and contribute to understanding of the contents.

Keywords: Education. Creative practice. Individual learning.

\section{Resumen}

El artículo analiza las relaciones entre la educación y la creatividad brasileña; y ejemplifica este contenido debido cuatro prácticas que estimulan la creatividad y contribuyen al aprendizaje. Para este estudio clasifica como cualitativo mediante procedimientos técnicos: revisión de la literatura y estudios de casos. Se observó que parte del problema relacionado con el interés y retener al estudiante en el sistema educativo brasileño se pueden resolver utilizando prácticas creativas que fomenten el interés y contribuyen a la comprensión de nuestros contenidos.

Palabras clave: Educación. La práctica creativa. La formación individual.

\section{Introdução}

Educação sempre foi um tema discutido no mundo no que diz respeito a sua importância para o crescimento em esferas tanto intelectuais, econômicos e sociais, seja para o indivíduo como para o coletivo. No Brasil isto não é diferente, pois é possível observar que existem mudanças necessárias no formato que a educação está aplicada. 
Para que as organizações de ensino possam acompanhar as mudanças do mercado de trabalho, é necessário que estes reformulem suas concepções de ensino e aprendizagem, para que possam, assim, proporcionar um espaço de mudança e divulgação do saber e, consequentemente gerar o desenvolvimento de novas aptidões. É necessário que se tenha um entendimento de que o processo de formação do indivíduo é contínuo e que não há uma terminalidade (ZILLI et al., 2010).

Uma das questões levantadas para estas mudanças está em estimular o indivíduo a aprender. E neste contexto entra a educação, que utiliza e instiga a criatividade do aluno. Afinal, no universo escolar, é fundamental o exercício da criatividade como elemento de propulsão no processo educativo (SENA e MARTINS, 2013).

Em seus estudos relacionadas à educação e criatividade, Robinson (2012) observou que a maioria das crianças se considera altamente criativa, ao contrário de grande parte dos adultos. Parte do motivo para esta involução da criatividade com nosso crescimento está no sistema de ensino atual, que inibi o processo criativo, por entender que uma tentativa por parte do aluno que não alcance o resultado esperado deve ser passível de castigo. Em muitos casos os professores e pais, sem querer, limitam as ações e atividades dos alunos, impedindo possíveis experiências que contribuam com potenciais realizações. O que devemos fazer é deixar o aluno saber que ele possui a capacidade para atender todos os desafios da vida - o trabalho do professor é decidir o quão duro eles vão trabalhar para enfrentar os desafios (STERNBERG e WILLIAMS, 1996). Neste contexto Robinson (2012) afirma que: "O desafio agora está em transformar os sistemas educacionais do século 21 . No centro dessa transformação precisa haver uma visão radicalmente diferente da inteligência e da criatividade humanas" (ROBINSON, 2012).

Desta forma, o objetivo deste estudo é apresentar exemplos de aplicações da criatividade na educação brasileira contemporânea. Para isso, a pesquisa caracterizou-se, do ponto de vista de sua natureza, como aplicada; quanto a abordagem do problema, se apresenta 
como uma pesquisa qualitativa; em relação aos seus objetivos, define-se como exploratória; e com base nos procedimentos técnicos, aplicam-se tanto a pesquisa bibliográfica como o estudo de casos (SILVA e MENEZES, 2001).

$\mathrm{Na}$ questão bibliográfica foram apresentados tanto um panorama da educação brasileira como um entendimento em relação a criatividade humana. Posteriormente, os dois contextos foram discutidos conjuntamente. Para exemplificar esta relação, foram levantadas e apresentadas quatro aplicações de práticas criativas na educação brasileira, exemplificando atividades e conteúdos de ensino diferentes entre si. Para isto limitou-se a busca por demonstrações registradas em vídeo, disponíveis no website Youtube utilizando como palavra-chave "Criatividade no Ensino". Foi adotado como requisito para seleção das atividades, serem pauta de programas jornalísticos. Este procedimento justifica-se uma vez que tais aplicações são consideradas inusitadas ainda na prática do ensino, por este motivo resultam em conteúdo de destaque neste meio.

\section{Educação Brasileira}

A constituição brasileira, por meio da Lei $9.394^{1}$, garante o direito ao ensino desde seu nível fundamental. Segundo Cury (2002, p. 170), "a ideia de desenvolvimento do educando nestas etapas que formam um conjunto orgânico e sequencial é o do reconhecimento da importância da educação escolar para os diferentes momentos destas fases da vida [...]".

Apesar do governo afirmar este direito, um dos principais problemas observados era a garantia real dele. No Brasil, até a década de 60 , o ingresso ao sistema de ensino era restrito a relativamente poucos alunos. Esse quadro começou a ser alterado nas décadas de 60 e 70,

1 Disponível em: http://www.planalto.gov.br/ccivil_03/leis/l9394.htm. Acesso em: 10/08/2014. 
quando houve um aumento expressivo da demanda por educação, no país. Na década de 80 , o acesso à escola ainda constituía uma questão prioritária na agenda governamental, mas somente no ano 2000 foi observada uma tendência à sua universalização, no ensino fundamental (GONÇALVES et al., 2008).

Mesmo com todas as dificuldades, o direito ao ensino é mantido, contudo, o contraponto não está no educando ter acesso ao sistema educacional, mas sim manter-se nele. Como discute Gonçalves et al. (2008), uma vez que a questão do acesso à escola está em vias de ser solucionado, nos últimos anos a atenção dos pesquisadores brasileiros tem sido direcionada basicamente para os problemas da repetência e da evasão.

Nos últimos anos, as políticas voltadas à área da educação estão sendo concentradas, basicamente, na questão da qualidade educacional, que tem sido mensurada principalmente através de testes padronizados de rendimento ou por meio do desempenho escolar do aluno. Diante desses resultados, é importante que os formuladores de políticas educacionais implementem medidas que favoreçam a permanência do aluno na escola, de forma que não seja preciso ele abandonar os estudos para inserir-se no mercado de trabalho. Igualmente importante é a adoção de medidas, pelas escolas, que garantam o bom desempenho do aluno no ano letivo corrente para assegurar a sua progressão nos anos letivos subsequentes (GONÇALVES et al., 2008). Para isto novos modelos de ensino são discutidos.

Arelaro (2005) afirma que o primeiro impasse do ensino público no Brasil diz respeito à necessidade de se criar um modelo de referência de "qualidade escolar", em que o ensino para todos possa significar, genuinamente, "ensino de qualidade para todos". O autor discute que, neste contexto, devemos admitir que a criança está em constante processo de aprendizado desde que nasce, o que obrigaria a uma reestruturação de todo o ensino básico, em especial da educação infantil e do ensino fundamental. 
Segundo Robinson (2012) os atuais sistemas educacionais não foram projetados para atender às demandas que enfrentamos hoje. Foram criados para satisfazer necessidades de uma era que já passou. Não basta fazer reformas: é preciso recriar estes sistemas. Como complementa Fontoura (2002), o ensino com base no especialismo, deve dar lugar a um formato onde o espírito inovador, a imaginação criadora e inventiva sejam prioridade.

Antes mesmo de aprendermos a falar, as imposições e negativas são apresentadas a nós. O "não" pode ser considerada uma das primeiras palavras que compreendemos. Tal sistema continua em nossa educação, seja pelos pais ou pela escola. O que leva a um ensino baseado na recompensa ou castigo. Contudo, é este sistema que contribui para "minar" a criatividade cultivada pela curiosidade infantil. Como afirma Robinson: "As formas predominantes no sistema educacional agem de modo a sufocar as condições essências para o desenvolvimento da criatividade; por isso, quando estudantes concluem o ensino médio, muitos já perderam a confiança criativa" (ROBINSON, 2012).

Em sua palestra apresentada no TED 2006 intitulada "Escolas matam a criatividade?"3 Ken Robinson afirma que as crianças têm uma grande capacidade de inovar, contudo tiramos isto delas. O autor complementa que as crianças não têm medo de errar, afinal quando não sabem a resposta elas inventam. E isto é o poder criativo inerente em cada ser humano desde que nasce. O ponto aqui discutido está em manter este espírito criativo, trabalhando nele continuamente.

2 Acrônimo para Technology, Entertainment, Design. É uma organização sem fins lucrativos dedicada à difusão das ideias, geralmente sob a forma de palestras.

3 Disponível em: http://www.ted.com/talks/ken_robinson_says_schools_kill_creativity?language=pt-br 


\section{Criatividade}

Apesar dos conceitos iniciais para criatividade estarem ligados às artes e à estética, atualmente é adotada uma abordagem que está ligada ao capital humano. Discussões sobre criatividade são atreladas principalmente ao mundo dos negócios. Pessoas criativas são vistas como o recurso necessário para atender e conquistar mercados (CROPLEY, 2001).

Amabile (2012) considera que a criatividade é a resposta, produto ou solução para uma tarefa em aberto. Contudo, o resultado também deve ser adequado à tarefa a ser concluída, ou o problema a ser resolvido; ou seja, ele deve ser valioso, correto, viável, ou de alguma forma apropriado. Já como descrito por King e Schilicksupp (1999) a criatividade é a capacidade das pessoas gerarem novos projetos, produtos, ou ideias que, até aquele momento, eram completamente desconhecidos do criador. Estas ideias podem ser resultado de pensamento imaginativo ou de uma combinação de pensamentos e formação de novos padrões ou pode, ainda, advir das experiências de um grupo. Para Cropley (2001) criatividade poderia ser conceituada como um conjunto de propriedades pessoais dentro de um indivíduo que pode levar a pessoa a se comportar de forma criativa.

De forma mais minimalista, Robinson (2012) define em poucas palavras que criatividade é o processo de desenvolver ideias originais que contenham valor. Independente do conceito adotado, a criatividade é inerente ao homem desde que este nasce. O problema é manter esta capacidade de conectar pensamentos de forma antes não associados. Como afirma Obregon et al. (2011), as pessoas criativas geralmente tiveram uma infância na qual possuíam liberdade para desenvolver suas próprias potencialidades. Segundo o próprio autor, a criatividade, neste contexto, pode ser considerada um fenômeno infinito, plural e multifacetado que apresenta grande dificuldade de conceituação precisa. 
Neste intuito de manter, ou mesmo ampliar nossa criatividade, ela deve ser estimulada e treinada. Para Zilli et al. (2010), os indivíduos criativos precisam ser incitados no seu comportamento organizacional, e a partir dos estímulos propiciados, o comportamento criativo se tornará uma constante, tanto na inovação quanto na resolução e transformação de problemas em oportunidades. Ou seja, a criatividade é ampliada quando uma pessoa intrinsecamente motivada, experiente e com habilidade para o pensamento criativo, trabalha em um ambiente que a estimula para tal (AMABILE, 2012).

Seguindo este pensamento, Robinson (2012) afirma que um dos principais motivos que levam as pessoas a acreditarem que não possuem potencial criativo é a formação que tiveram. O autor completa que não se trata de adquirir capacidade criativa, mas sim de preservá-la.

Importante também é a exposição a condições de vida favoráveis ou desfavoráveis. Circunstâncias favoráveis envolvem fatores como tolerância para o novo, incentivo e reconhecimento (CROPLEY, 2001). Contudo, as capacidades criativas de uma pessoa podem ser ainda mais desenvolvidas se intensificarmos o uso e a prática, o treinamento formal e informal e, através do suporte de colegas e gerentes (KING e SCHILICKSUPP, 1999). Nesta causa, um dos principais aliados deveria ser encontrado no sistema educacional.

\section{Criatividade na educação}

Como já apresentado, um dos principais problemas ligados ao desestímulo à criatividade está no sistema educacional. Obregon et al. (2011) descreve:

Para ser criativo o indivíduo tem de estar aberto a todas as alternativas. Entretanto, essa abertura mental nem sempre é possível, pois as pessoas constroem bloqueios no processo de maturação e socialização. 
Alguns desses bloqueios podem ter causas externas tais como: ambiente familiar, sistema educacional e burocracia organizacional; e outros bloqueios são gerados internamente pelas reações a fatores mentais e culturais (OBREGON et al., 2011).

O mesmo princípio é compartilhado por Zilli et al., (2010) o qual enfatiza que devemos estar atentos aos obstáculos organizacionais da criatividade. Espaços estes que não permitam ou inspirem o uso dos sentidos para introspeç̧ão e reflexão, bloqueando ou limitando a capacidade criativa dos seus colaboradores. Assim, providenciar suporte à cultura de criatividade contribui para que a personalidade das pessoas tenha a oportunidade de ter seu lado criativo desenvolvido, cabendo, portanto as organizações propiciarem um ambiente criativo e inovador que ofereça suporte para a criatividade dos indivíduos cresça (ZILLI et al., 2010).

Como organização de ensino, a escola deve trabalhar esse conceito de educação e criatividade, permitindo ao educando ser criativo e para isso, promovendo práticas de criatividade.

Como afirmam Henn e Prestes (2011) a criatividade é fundamental no contexto do ambiente escolar e precisa ser potencializada pelas ações pedagógicas, pois está presente em cada indivíduo, e todos possuem a capacidade ímpar e criadora. Tal capacidade é potencializada ou minimizada conforme as suas interações com o meio cultural, que pode ou não oferecer estímulos às atitudes e aos atos criativos. Como apresenta Cropley (2001), estimular esta criatividade inerente na criança seria o interesse particular dos educadores, em essência transformar o potencial em comportamento real. Neste contexto, Henn e Prestes (2011) complementam:

A criatividade promove, portanto, na esfera educacional, uma aprendizagem significante que promove a combinação do lógico e o intuitivo, do intelecto e os sentimentos, do conceito e a experiência, da ideia e o significado. Quando aprendemos dessa forma, somos, de fato, seres integrais, utilizando para tanto, todas as nossas capacidades (HIENN e PRESTES, 2011). 
Dessa forma, observamos que mudanças nas práticas de ensino podem colaborar com melhores resultados no aprendizado da criança, e assim práticas criativas forneceriam ferramentas adequadas neste contexto. Afinal, para pôr em prática ideias criativas, as pessoas precisam ter iniciativa, independência de pensamentos e ação, e flexibilidade (ZILLI et al., 2010). Como afirma Cropley (2001) o contato com modelos de comportamentos criativos e oportunidades adequadas, tais como a presença de instrumentos musicais, ferramentas especiais, ou literatura especializada, bem como pessoas que fomentam a criatividade é o motor para criatividade.

\section{Exemplos}

Atualmente, o modelo adotado para a educação não encoraja uma igualdade entre as linhas de conteúdo. Por que ciências e matemática são mais importantes que artes e educação física? Ou por que suas práticas não podem ser integradas formando novas e criativas opções de aprendizado? Afinal, como Fontoura (2002) afirma: "A interdisciplinaridade pode ser identificada como um caminho promissor para a formação integral do ser humano".

A importância de se obter uma educação mais abrangente e motivadora tem mobilizado os educadores na busca de alternativas que supram as carências encontradas em determinados métodos de ensino. Como afirmam Bocconi et al. (2012), no cerne do conceito de uma sala de aula criativa, permeiam práticas pedagógicas inovadoras que surgem quando os professores utilizam as tecnologias da informação e comunicações nos seus esforços para organizar novas e melhoradas atividades de aprendizagem, em vez de simplesmente investir em pedagogias tradicionais.

Atualmente a educação busca um ensino mais humano, voltado para os reais interesses dos alunos e propício para a atuação dos mesmos como principais agentes do seu processo educacional, enfatizando suas potencialidades, habilidades e competências (HENN e PRESTES, 2011). Bocconi et. al. (2012) quando discutem propostas para uma sala de aula 
criativa, destacam que uma das dimensões que devem ser adotadas no processo de aprendizagem do aluno seria das práticas de aprendizagem flexíveis, lúdicas e envolventes, atendendo às necessidades e expectativas individuais dos estudantes.

Atualmente, a busca por exemplos de práticas criativas aplicadas ao ensino é facilitada principalmente pelas ferramentas ligadas à internet. Contudo, nota-se nestes procedimentos que as principais referências em vídeo são apresentadas como conteúdo da mídia jornalística. Por esta característica, pressupõe-se que tais ações são consideradas ainda como algo incomum a prática regular de ensino, merecendo destaque por parte da imprensa. Contudo, continuam como bons exemplos de inciativas adotadas por agentes educadores. Como afirmam Sternberg e Williams (1996) o professor deve servir como um modelo para o comportamento criativo, pois assim pode-se esperar que os alunos se envolvam com a mesma conduta. Desta forma, são apresentadas quatro destas práticas aplicadas em diferentes instituições para distintos conteúdos didáticos:

\section{Exemplo 1 - Física no dia a dia}

Iniciativa do Instituto de Física da USP, o "Show de Física” atende escolas públicas e privadas, apresentando experimentos ligados a este conteúdo com demonstrações de situações corriqueiras no dia a dia do aluno (Figura 1).

Desta forma, a participação do acadêmico é incentivada durante os experimentos. Muitas das atividades podem ser reproduzidas em sala de aula por meio de materiais de baixo custo. Curcio e Malanos (2011) afirmam que estratégias criativas as quais envolvam os alunos, com a finalidade de alcançar o efetivo processo ensino aprendizagem, devem ser utilizadas pelos professores em sala de aula. Os autores complementam que as pesquisas desenvolvidas por professores de Ciências, e em particular os de Física, levam sempre à conclusão de que através de aulas de laboratório convenientemente relacionadas ao desenvolvimento teórico, os alunos obtêm resultados muito melhores. 
Figura 1 - Ensino de Física Criativa

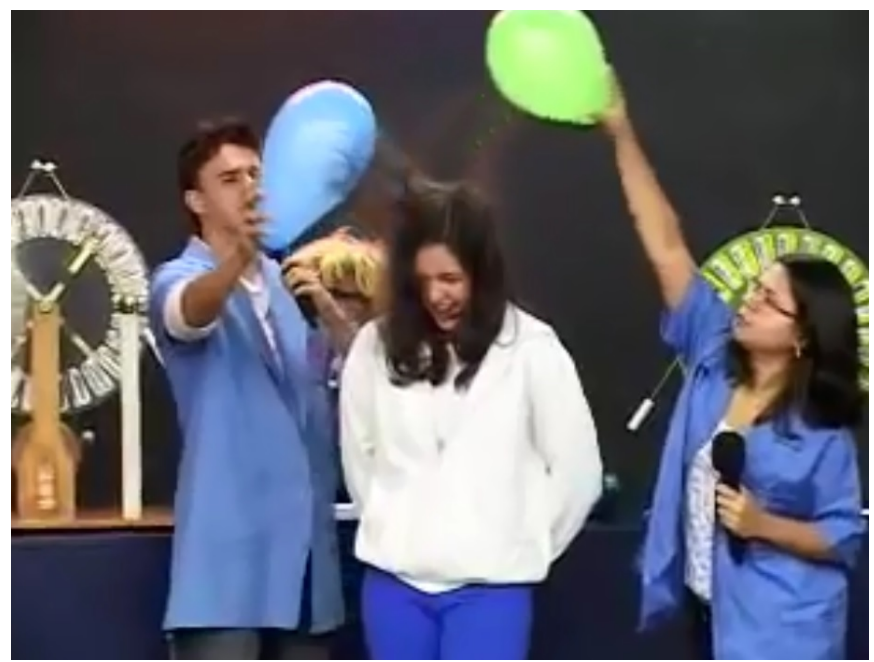

Fonte: Site TV Cultura ${ }^{4}$.

\section{Exemplo 2 - Teatro no Inglês}

Na cidade de Campo Grande, o professor de inglês adota o uso de teatro como avaliação no lugar das provas mensais (Figura 2). Esta prática é aplicada aos alunos do sexto ao nono ano do Ensino Fundamental, proporcionando além da compreensão do conteúdo posto em prática, a liberdade criativa na interpretação das peças baseadas em filmes ou animações populares entre os jovens. Segundo Koudela e Santana (2005) a história e a estética do teatro fornecem conteúdos e metodologias norteadoras para a teoria e prática educacional.

Além de incentivar os aprendizes a vivenciarem a oralidade em língua inglesa, em situações que os aproximam do uso real da língua-alvo,

4 Disponível em: <http://tvcultura.com.br/videos/26030_um-jeito-criativo-de-se-ensinar-fisica.html>. Acesso em: 08/08/2014. 
a prática teatral os possibilita a apropriação de tudo aquilo que a experiência pode lhes acrescentar cultural e socialmente (PEREIRA, 2011).

Figura 2 - Ensino do inglês com teatro

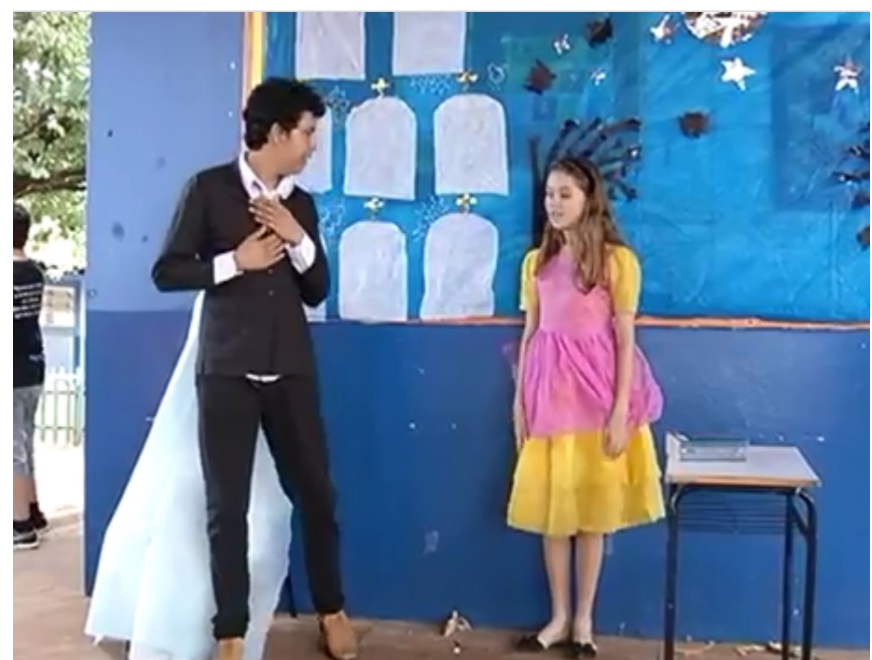

Fonte: TV Brasil Pantanal ${ }^{5}$.

\section{Exemplo 3 - Tecnologia Cambiante}

Não há dúvida se o computador deve ou não entrar nas escolas, o que precisa ser discutido é como ele pode ser inserido para favorecer o processo de educação e a universalização do conhecimento (ROSA, 2010). Exemplo disso está no projeto desenvolvido pela Microsoft que disponibiliza a tecnologia de forma itinerante a alunos de escolas públicas, proporcionando experiências de aprendizado através de gincanas educativas (Figura 3). Almeida e Prado (1999, p. 1) afirmam:

5 Disponível em: <https://www.youtube.com/watch?v=9plkbn6eRKc>. Acesso em: 08/08/2014. 
Hoje é consenso que as novas tecnologias de informação e comunicação podem potencializar a mudança do processo de ensino e de aprendizagem e que, os resultados promissores em termos de avanços educacionais relacionam-se diretamente com a ideia do uso da tecnologia a serviço da emancipação humana, do desenvolvimento da criatividade, da autocrítica, da autonomia e da liberdade responsável (ALMEIDA e PRADO, 1999, p.1).

Figura 3 - Tecnologia itinerante

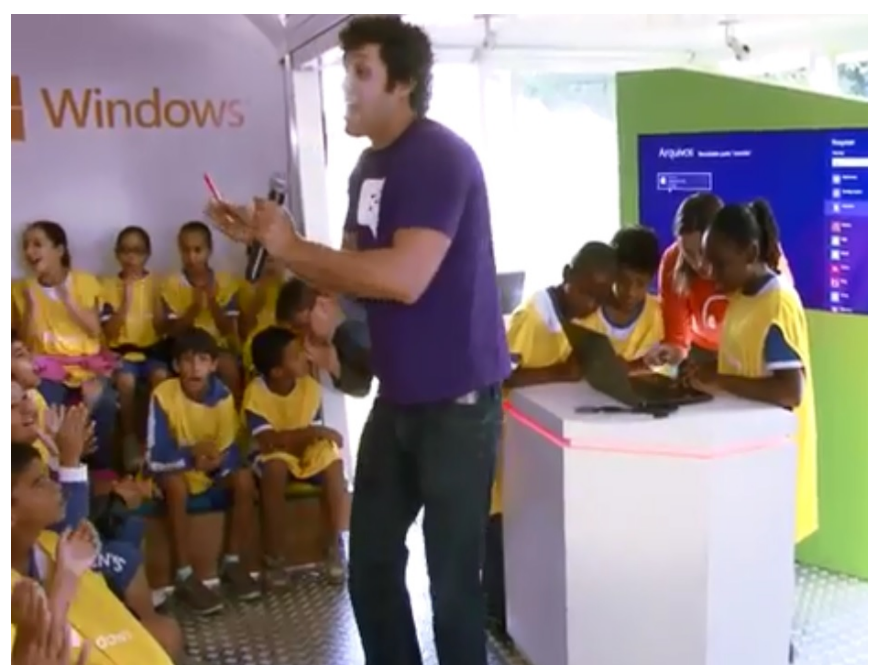

Fonte: Prefeitura de Santos ${ }^{6}$.

\section{Exemplo 4 - Gamificação}

Apesar dos exemplos anteriores serem compreendidos como uma forma de aplicação da educação através de jogos, o contexto aqui abordado para a "gamificação" está relacionada à pratica de jogos lúdicos que se utilizam de tabuleiros, dados ou peças de encaixe.

6 Disponível em: <https://www.youtube.com watch?v=g9Ydz_U5Mql>. Acesso em: 08/08/2014. 
Exemplo disso está na prática da rede municipal de Caçapava/SP. As atividades foram nomeadas como "A Matemática Descomplicada", e utilizam de jogos de encaixe ou do uso de dados numéricos (Figura 4). Estas atividades resultam em melhor compreensão do conteúdo. Como afirmam Sena e Martins (2013) educar refere-se à inclusão de brincadeiras, atividades e rotinas nos planejamentos que proporcionem o desenvolvimento da criatividade.

Figura 4 - Matemática descomplicada

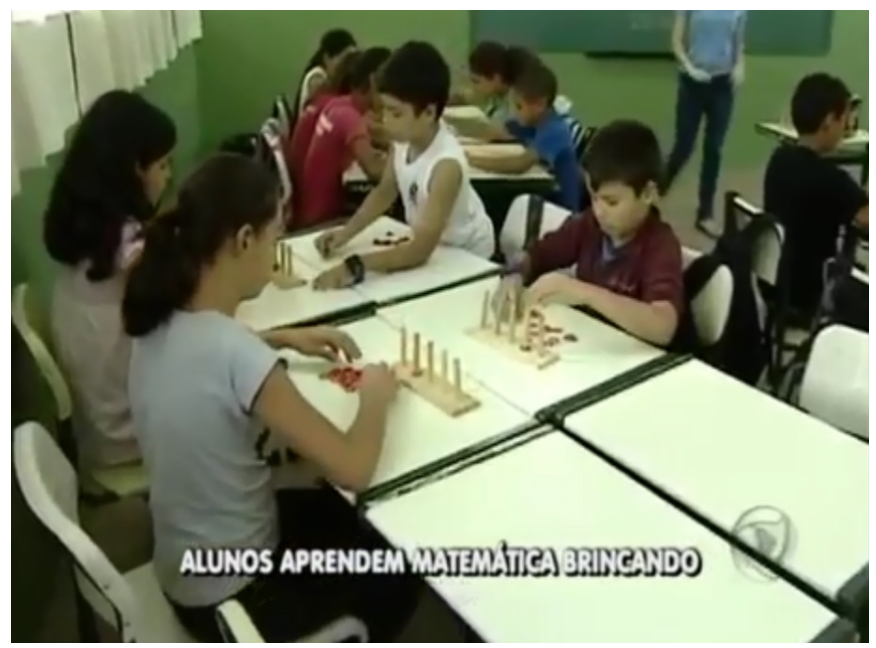

Fonte: Record São Paulo7.

7 Disponível em: <https://www.youtube.com/watch?v=QpufX8FAtTA>. Acesso em: 08/08/2014. 


\section{Considerações finais}

Apesar de nossa legislação registrar como obrigatória a educação desde o ensino fundamental, ela não garante a passagem eficiente dos conteúdos ministrados como a permanência do acadêmico no sistema de ensino.

Parte deste problema pode ser solucionado utilizando práticas criativas que estimulem o interesse e contribuam para a compreensão dos temas por parte dos alunos. Apesar de serem atividades isoladas e iniciadas por professores interessados no crescimento do aluno, merecendo inclusive registro como pauta jornalística, os exemplos apresentados demonstram a potencialidade do uso da criatividade na educação.

O artigo apresenta uma discussão inicial sobre o assunto. Contudo, é observado um vasto campo para aplicação de pesquisas direcionadas, principalmente a novos formatos de ensino, assim como no desenvolvimento de atividades que possam contribuir no processo educativo criativo do ensino brasileiro. Pois, no final, o que importa não é apenas aprender, mas a experiência que se tem com o aprendizado.

\section{Referências}

ALMEIDA, M. E. B.; PRADO, M. E. B. B. Um retrato da informática em educação no Brasil. 1999.

AMABILE, T. M. Componential theory of creativity. Working Paper. Boston: Harvard Business School, 2012. Disponível em: <http://www.hbs.edu/faculty/ Publication\%20Files/12-096.pdf〉. Acesso em: 15 jan. 2015.

ARELARO, L. R. G. O ensino fundamental no Brasil: avanços, perplexidades e tendências. Educ. Soc., Campinas, v. 26, n. 92, p. 1039-1066, Especial - Out. 2005. 
BOCCONI, S.; KAMPYLIS, P.; PUNIE, Y. Innovating teaching and learning practices: Key elements for developing creative classrooms in Europe. Luxembourg: Publications Office of the European Union, 2012.

CURCIO, Í. F.; MALANOS, M. J. A física experimental no ensino médio para alunos das redes públicas municipais e estaduais. In: CONGRESSO INTERNACIONAL DE CRIATIVIDADE INOVAÇÃO. 2011. Manaus. Anais..., Manaus , 2011. p. 222-241.

CURY, C. R. J. A educação básica no Brasil. Educ. Soc., Campinas, v. 23, n. 80, p. 168-200, set. 2002.

CROPLEY, A. J. Creativity in education and learning: A guide for teachers and educators. London: Kogan, 2001.

FONTOURA, A. M. EdaDe: a educação de crianças e jovens através do design. Tese (Doutorado em Engenharia de Produção) - Universidade Federal de Santa Catarina, Florianópolis, 2002.

GONÇALVES, M. E.; RIOS-NETO, E.; CÉSAR, C. C. Evasão no ensino fundamental brasileiro: identificação e análise dos principais determinantes. In: ENCONTRO NACIONAL DE ESTUDOS POPULACIONAIS. 2008. Caxambu. Anais... Caxambu, 2008.

HENN, S.; PRESTES, R. A. A criatividade na prática pedagógica como ferramenta de aquisição de habilidades e competências no AEE. In: CONGRESSO INTERNACIONAL DE CRIATIVIDADE INOVAÇÃO. 2011. Manaus. Anais..., Manaus, 2011. p. 214-221.

KING, B.; SCHLICKSUPP, H. Criatividade: uma vantagem competitiva. Rio de Janeiro: Qualitymark, 1999.

KOUDELA, I. D.; SATANA A. P. de. Abordagens metodológicas do teatro na educação. Ciências Humanas em Revista, Universidade do Vale dos Sinos, v. 3, n. 2, dez. 2005. 
OBREGON, R. de F. A.; et al. A interação como elemento constitutivo dos processos de desenvolvimento da criatividade. In: CONGRESSO INTERNACIONAL DE CRIATIVIDADE INOVAÇÃO. 2011. Manaus. Anais ... Manaus, 2011. p. 255-267.

PEREIRA, T. C. M. O teatro como estímulo à aprendizagem de Língua inglesa: a experiência em uma escola pública. Dissertação (Mestrado em Linguística Aplicada) - Universidade do Vale do Sinos, São Leopoldo, 2011.

PREFEITURA DE SANTOS. Tecnologia a favor do aprendizado de crianças da rede municipal. Disponível em: <https://www.youtube.com/watch?v=g9Ydz U5MqI $>$. Acesso em: 08 ago. 2014.

ROBINSON, K. Libertando o poder criativo: a chave para o crescimento pessoal e das organizações. $1^{\text {a }}$ ed. São Paulo: HSM, 2012.

ROSA, C. P. O computador como ferramenta pedagógica na educação infantil. In: V CONGRESSO DE PESQUISA E INOVAÇÃO DA REDE NORTE NORDESTE DE EDUCAÇÃO TECNOLÓGICA. Maceió, nov. 2010. Disponível em: <http://connepi. ifal.edu.br/ocs/index.php/connepi/CONNEPI2010/paper/viewFile/1018/769>. Acesso em: 20 set. 2014.

SENA, A. B. T. de; MARTINS, J. P. O desenvolvimento da criatividade na educação infantil e sua contribuição na aprendizagem da educação matemática nas series iniciais do ensino fundamental. Revista Científica Semana Acadêmica, Fortaleza, v. 1, n. 7,2013. Disponívelem: <http://semanaacademica.org.br/o-desenvolvimento-da-criatividade-na-educacao-infantil-e-sua-contribuicao-na-aprendizagem-da $>$. Acesso em: 03 out. 2014.

SILVA, E. L. da; MENEZES, E. M. Metodologia da pesquisa e elaboração de dissertação. Florianópolis: Laboratório de Ensino a Distância da UFSC, 2001.

STERNBERG, R. J.; WILLIAMS, W.M. How to developstudent creativity. Alexandria: Association for Supervision and Curriculum Development, 1996.

TV BRASIL PANTANAL. Teatro em inglês nas escolas públicas. Disponível em: <https://www.youtube.com/watch?v=9pIkbn6eRKc〉. Acesso em: 08 ago. 2014. 
TV CULTURA. Um jeito criativo de se ensinar física. Disponível em: <http:// tvcultura.com.br/videos/26030_um-jeito-criativo-de-se-ensinar-fisica.html >. Acesso em: 08 ago. 2014.

TV RECORD. Alunos aprendem matemática brincando. Disponível em: <https:// www.youtube.com/watch?v=QpufX8FAtTA >. Acesso em: 08 ago. 2014.

ZILLI, A. R. et al. Criatividade como diferencial nas organizações de ensino superior. In: COLÓQUIO INTERNACIONAL SOBRE GESTIÓN UNIVERSITARIA EM AMÉRICA DEL SUR, 10. 2010. Mar del Plata. Anais..., Mar del Plata, 2010.

Recebido: 12/01/2015

Received: 01/12/2015

Aprovado: 19/12/2016

Approved:12/19/2016 
